\title{
LAS PLATAFORMAS DIGITALES EN EL DESARROLLO DEL ENOTURISMO EN CASTILLA Y LEÓN: PÁGINAS WEB Y REDES SOCIALES
}

\author{
Julio Fernández Portela \\ Universidad Nacional de Educación a Distancia (UNED) \\ https://orcid.org/0000-0002-1677-8103 \\ Carlos J. Pardo Abad \\ Universidad Nacional de Educación a Distancia (UNED) \\ https://orcid.org/0000-0003-0047-5834
}

\section{RESUMEN}

El enoturismo es una actividad económica en crecimiento en Castilla y León. Cada vez son más las personas interesadas en conocer el mundo de la vid y el vino, convirtiéndose en uno de los pilares del desarrollo rural en las llanuras del Duero. Para lograr este papel clave en el territorio, esta actividad ha tenido que adaptarse a los cambios en los gustos de los consumidores y, en especial, a las nuevas formas de comunicación digital, más rápidas y directas. Con este trabajo se pretende ver la situación existente en las bodegas castellanoleonesas en el ámbito de las nuevas tecnologías y, en especial, de las páginas web y redes sociales, dos herramientas claves para el desarrollo del turismo enológico.

Palabras clave: Castilla y León; enoturismo; páginas web; redes sociales; desarrollo rural.

\section{Digital platforms in the development of wine tourism in Castilla y León: web pages and social networks}

\begin{abstract}
Wine tourism is a growing economic activity in Castilla y León. More and more people are interested in knowing the ins and outs of the world of wine, so wine is becoming one of the pillars of rural development in the plains of the Duero. In order to achieve this key role in
\end{abstract}

Fecha de recepción: 22 de febrero de 2019

Fecha de aceptación: 15 de julio de 2019

Departamento de Geografía. Universidad Nacional de Educación a Distancia (UNED). Paseo Senda del Rey, 7.28040 MADRID (España).E-mail: jfportela@geo.uned.es, cjpardo@geo.uned.es 
the territory, this activity has had to adapt to changes in the tastes of consumers and, especially, to faster and more direct new forms of communication.

This paper aims to outlook the existing situation in the wineries of Castilla y León in the field of new technologies and, especially, of websites and social networks, two key tools for the development of wine tourism.

Keywords: Castilla y León; wine tourism; website; social networks; rural development.

\section{INTRODUCCIÓN}

Esta investigación se enmarca dentro de la región de Castilla y León, un territorio que posee una importante actividad vitivinícola clave para su desarrollo socioeconómico. La industria vitivinícola se consolida como una actividad agroalimentaria capaz de diversificar la economía del medio rural, basada principalmente en la actividad agraria. El cultivo de la vid, y la posterior transformación de la uva en vino, han generado un entramado empresarial que ha sido capaz de crear nuevos empleos y, en ocasiones, asentar nuevos pobladores en un medio rural que languidece económica y socialmente, y donde el problema del abandono de la población junto con el fuerte envejecimiento, son los dos retos a combatir en los próximos años. Además del empleo generado con esta actividad, cuidado de las viñas y trabajo en bodega, hay que añadir el interés que ha despertado el mundo del vino entre la población y su deseo de visitar las instalaciones de elaboración y el campo, dando lugar al enoturismo, una tipología turística en expansión que constituye uno de los pilares del desarrollo rural de una parte importante de los municipios localizados a lo largo del río Duero y en sus proximidades. Esta actividad económica está acompañada de la apertura de hoteles y casas rurales, restaurantes, tiendas de productos típicos, museos y oficinas de turismo, en definitiva, de una serie de servicios destinados a crear un tejido económico que está convirtiendo al binomio vino y turismo en un motor clave para el desarrollo rural de una parte importante de las llanuras centrales de la Comunidad Autónoma.

\section{PERSPECTIVAS TEÓRICAS Y METODOLÓGICAS}

El tema del enoturismo ha despertado un interés creciente en los últimos años y las investigaciones realizadas al respecto se han hecho más especializadas, con aproximaciones tanto conceptuales como de análisis de casos concretos. Es decir, estudios a veces teóricos y en otras ocasiones descriptivos sobre los vínculos existentes entre turismo enológico, territorio, patrimonio natural y cultural y desarrollo regional sostenible. Como consecuencia de la importancia científica de esta actividad turística, general en la mayor parte de los países desarrollados, fue la celebración de la primera Conferencia Internacional sobre Enoturismo en el año 2004'1.

1 Esta primera Conferencia se celebró en el mes de mayo de 2004 en Margaret River, localidad situada en el suroeste de Australia Occidental, en el valle del río homónimo y a 277 kilómetros al sur de Perth. Margaret 
El turismo enológico ha sido definido como la visita a viñedos, bodegas, festivales del vino y demostraciones vitivinícolas, experimentando las características de un determinado tipo de uva y vino en una región en particular (Halle et al., 2000). Esta definición, simple y muy directa en lo que se refiere a precisión terminológica, ha sido ampliamente utilizada en gran parte de la literatura científica publicada al respecto, sobre todo en el ámbito anglosajón (Dodd, 2000; Charters y Ali-Knight, 2002; Heaney, 2003; Alant y Bruwer, 2004).

El turismo del vino es un tipo de turismo temático en el que se combinan unos elementos muy característicos y fundamentales, como vino, gastronomía local, cultura y factores adyacentes (López-Guzmán, Rodríguez García y Vieira Rodríguez, 2013). La combinación de estos elementos, y otros de tipo secundario, crean un producto muy concreto que está logrando promover la economía local y la preservación ambiental de numerosas comarcas vitivinícolas.

El turismo del vino fue inicialmente interpretado como una actividad complementaria de otros turismos principales con mayor demanda y tradición, pero en la actualidad es considerado principalmente como resultado de un conjunto de motivaciones y atracciones que generan viajes específicos destinados a conocer la realidad de los viñedos, el vino y las bodegas de amplios espacios geográficos². Es decir, destinados a conocer la realidad de aquellos elementos propios de los denominados como "paisajes del vino" (Brunori y Rossi, 2000). En estos desplazamientos, el turista se convierte en enoturista al vivir una experiencia completa de carácter sensorial basada en sabores, olores y colores, que identifica e individualiza como en ningún otro caso esta actividad turística (Getz, 2000).

En los principales países productores de vino, el enoturismo ha logrado alcanzar un importante volumen de visitantes. Especialmente significativa es la demanda de países como Estados Unidos y Australia. En el primer caso, el valle de Napa recibe millones de visitantes anuales y pasa por ser el primer destino enoturístico del mundo. Localizado en el Estado de California, este valle concentra más de 300 productores de vino y representa el éxito de la nueva industria enológica y su difusión turística.

El nivel de desarrollo del turismo enológico no es uniforme y existen grandes diferencias entre los países más y menos desarrollados (Mitchell y Hall, 2006). En este sentido, y dentro de un ámbito geográfico relativamente reducido como la cuenca mediterránea, es muy significativa la diferencia existente entre países como Francia, Italia y España, con elevadas cifras de turistas del vino, y Grecia, Chipre, Turquía o los países balcánicos. El enoturismo refleja, de alguna manera, los niveles de desarrollo de los países, regiones y comarcas como consecuencia de ser un nicho muy especializado en la actividad turística global (Kunc, 2010).

River es una es una de las regiones vitícolas más representativas del país, con una comercialización muy intensa de vinos desde finales de la década de 1980.

2 En este tipo de turismo las bodegas, tanto actuales como históricas, desempeñan un papel fundamental por el atractivo técnico de sus arquitecturas. Además son también motivo de visita para un turismo de patrimonio industrial que ha experimentado, casi en paralelo con el enoturismo, un auge muy significativo en los últimos tiempos. Más allá del ámbito estrictamente vinícola, las bodegas son referentes monumentales e identitarios de muchas localidades y comarcas rurales. Es lo que sucede en Jerez de la Frontera (Cádiz), en donde las afamadas bodegas, con visitas programadas desde el siglo XVIII, alcanzan sin complejos la condición de "catedrales del vino". 


\subsection{Vías de aproximación metodológica}

Las investigaciones en el turismo del vino se inician en Australia y Nueva Zelanda a mediados de la década de 1990. Comenzaron centrándose tanto en su repercusión en el medio rural, con referencia en espacios vitivinícolas representativos, como en el comportamiento y preferencias de visita de los turistas.

Más recientemente, la investigación enoturística se ha extendido por un número amplio de países y el turismo del vino es analizado como una vía complementaria de creación de empleo, de generación de riqueza, de configuración de una imagen turística de calidad y de preservación de importantes recursos naturales y culturales. Los beneficios, por lo tanto, son amplios y de variada naturaleza y en su consecución juega un rol fundamental la imagen que proyectan las bodegas sobre el turista y el consumidor.

En la actualidad existe un cuerpo muy extenso de conocimientos en torno a este turismo. El método aplicado ha sido, y sigue siendo, básicamente descriptivo y toma como referencia de estudio las fuentes de información, casos concretos de análisis a nivel nacional, regional o local, eventos y muestras, etc. Es decir, un método enfocado sobre todo a responder a las preguntas de "quién" y "qué", y menos el "cómo" y "por qué" (Jennings, 2001).

El método descriptivo se ha mostrado clave en el objetivo primordial de caracterizar una actividad inicialmente poco demandada y conocida. Ha sido una primera fase metodológica que está progresivamente dando paso a una segunda, en la que prevalece el complejo y variado campo explicativo, causal, comparativo, evaluativo o predictivo. Sin embargo, y siguiendo lo que apuntan algunos autores, aún es muy escasa en esta segunda fase la utilización más sofisticada de técnicas cualitativas y cuantitativas que amplíen la comprensión del fenómeno enoturístico (Mitchell y Hall, 2006).

De forma complementaria al método empleado, bien descriptivo o explicativo, la aproximación científica puede clasificarse en dos grandes marcos analíticos distintos: el macroeconómico y el microeconómico. Esta doble clasificación es de tipo jerárquica o estratégica, en la que destacan los estudios de ámbito internacional, nacional o regional en el primer caso, y los referidos a bodegas concretas en el segundo (Carlsen, 2004). Es de esperar que estos dos grandes marcos analíticos alcancen la necesaria complementariedad, integrándose las investigaciones más centradas en las cifras sobre producciones, comercialización o visitas globales con aquellas otras que estudian la orientación turística concreta de bodegas y viñedos.

Solo con un estudio complementario y combinado de ambos modos de aproximación metodológica se podría comprender el verdadero potencial que presenta el turismo del vino. Las visitas en torno al vino, las bodegas y los viñedos no son, en sí mismas, un fenómeno nuevo, pero los modernos estudios turísticos aún tienen pendiente incidir en algunos aspectos muy relevantes, como los factores reales de tipo económico, técnico, cultural, geográfico o vocacional que motivan estos desplazamientos.

\subsection{Revisión de enfoques científicos y objetivos generales de análisis}

La importancia que ha adquirido el enoturismo ha conllevado un significativo incremento de las investigaciones, con enfoques distintos y, aunque complementarios, variados 
objetivos científicos. Esta ampliación del estado de la cuestión llevará inevitablemente aparejada la aparición de nuevas líneas de análisis e interpretación.

Las investigaciones se extendieron rápidamente desde comienzos de la década de 1990 y aproximadamente dos tercios de toda la literatura científica proceden de Australia y Nueva Zelanda. Estos dos países no solo tienen un sustancial turismo enológico sino también una larga trayectoria en investigación sobre comercialización del vino. En el tercio restante de las publicaciones predominan las procedentes de Estados Unidos, Canadá y Suráfrica, con importantes áreas vitivinícolas dedicadas al turismo.

En conjunto, Mitchell y Hall (2006) identifican siete grandes temas que abordan los estudios del turismo enológico, unidos casi siempre por la circunstancia de que los métodos empleados son aun escasamente innovadores y muy acusada en todos ellos la tendencia al análisis exclusivamente regional y descriptivo. Los temas son los siguientes: (i) el producto enoturístico y su desarrollo; (ii) el turismo del vino y el desarrollo regional; (iii) el alcance de las visitas a las bodegas y viñedos; (iv) las características de los visitantes; (v) el comportamiento del enoturista; (vi) el nivel de satisfacción del visitante y sus motivaciones; y (vii), finalmente, un campo de investigación reciente y cada vez más importante sobre los riesgos de bioseguridad planteados por los visitantes (Tabla 1).

\section{Tabla 1 \\ LOS GRANDES TEMAS DE INVESTIGACIÓN ENOTURÍSTICA}

\begin{tabular}{ll}
\hline \multicolumn{1}{c}{ Tema } & \multicolumn{1}{c}{ Rasgos básicos de análisis } \\
\hline $\begin{array}{l}\text { El producto enoturístico y su } \\
\text { desarrollo }\end{array}$ & - Trascendencia turística de las empresas vitivinícolas. \\
& $\begin{array}{l}\text { - Características de las bodegas, rutas del vino, festivales, museos } \\
\text { temáticos, etc. }\end{array}$ \\
\hline $\begin{array}{l}\text { El turismo del vino y el } \\
\text { desarrollo regional }\end{array}$ & - Impacto social y económico del turismo del vino en las zonas \\
& $\begin{array}{l}\text { receptoras. } \\
\text { - Alcance del turismo del vino en el desarrollo de las comunidades } \\
\text { locales: creación de empleo, fomento de producciones locales e }\end{array}$ \\
& impulso de otras ofertas turísticas. \\
El alcance de las visitas a las & - Dificultad en la cuantificación precisa de la demanda de visita, \\
bodegas y viñedos & $\begin{array}{l}\text { entre otras razones por la ausencia de métodos uniformes que } \\
\text { permitan conocer estimaciones y hacer comparaciones. }\end{array}$ \\
Las características de los & - Perfil sociodemográfico de los turistas: edad, procedencia, nivel \\
visitantes & profesional y de estudios, etc. \\
El comportamiento del & - Estudio de una serie de indicadores básicos: tiempo de visita, \\
enoturista & número de bodegas o viñedos visitados, gasto efectuado, \\
& $\begin{array}{l}\text { realización de actividades complementarias, repetición de visita, } \\
\text { etc. }\end{array}$ \\
\hline
\end{tabular}




\begin{tabular}{ll}
\multicolumn{1}{c}{ Tema } & \multicolumn{1}{c}{ Rasgos básicos de análisis } \\
\hline $\begin{array}{l}\text { El nivel de satisfacción del } \\
\text { visitante y sus motivaciones }\end{array}$ & $\begin{array}{l}\text {-Aproximación al grado de satisfacción del viajero en su visita } \\
\text { enoturística y las causas que motivan ese desplazamiento. }\end{array}$ \\
$\begin{array}{l}\text { Los rasgos de bioseguridad } \\
\text { planteados por los visitantes }\end{array}$ & $\begin{array}{l}\text { Análisis de riesgos derivados de las visitas a unos enclaves } \\
\text { considerados de producción de un alimento, el vino y, por lo } \\
\text { tanto, sensible para la salud humana. }\end{array}$ \\
\hline
\end{tabular}

Fuente: Mitchell y Hall, 2006 y elaboración propia.

Una propuesta de revisión de enfoques muy interesante es la base de datos realizada desde el Centre International de Recherches et d'Études Touristiques (CIRET), en Aix-en-Provence (Francia), categorizando las publicaciones enoturísticas aparecidas en las últimas décadas a nivel mundial (Carlsen y Charters, 2006) (Tabla 2). El grupo más frecuente de temas aparecidos en la investigación sobre turismo del vino podría ser descrito como "enoturismo, cultura y patrimonio", en el que se incluirían aspectos relacionados con la mejora del patrimonio, conservación, cultura y autenticidad. Esto se relaciona con el hecho de que el turismo del vino se desarrolla intensamente en áreas geográficas identificadas con importantes destinos de turismo cultural y patrimonial, tal y como sucede en Europa.

Tabla 2

CATEGORIZACIÓN DE LAS PUBLICACIONES ENOTURÍSTICAS

\begin{tabular}{|ll}
\hline \multicolumn{1}{c}{ Grupo } & \multicolumn{1}{c}{ Referencias concretas } \\
\hline Enoturismo, cultura y patrimonio & $\begin{array}{l}\text {-Mejora del patrimonio vitivinícola, conservación, cultura y } \\
\text { autenticidad de los lugares }\end{array}$ \\
\hline Negocio del turismo enológico & $\begin{array}{l}\text {-Gestión, desarrollo, impacto económico, turismo enológico } \\
\text { internacional, festivales del vino, etc. }\end{array}$ \\
& -Análisis coste-beneficio. \\
\hline Comercialización del enoturismo & -Estudios de mercado, destino, promoción, imagen e \\
& identidad enoturística. \\
& -Percepción y lealtad de marca. \\
\hline Comportamiento de los enoturistas & -Consumo, frecuencia de visitas, motivación personal, gastos \\
& o toma de decisiones. \\
& -Experiencias anteriores y preferencias actuales o futuras. \\
& -Regiones, modelos, políticas, asociaciones y cooperación. \\
\hline
\end{tabular}

Fuente: Centre International de Recherches et d'ÉtudesTouristiques (CIRET), según Carlsen y Charters (2006), y elaboración propia.

Siguiendo al CIRET, otro importante grupo temático podría ser denominado como el del "negocio del turismo enológico". En él se incluiría lo vinculado a la gestión y 
desarrollo, impacto económico, turismo internacional, festivales del vino, análisis costebeneficio, etc.

El tercer grupo va referido a la "comercialización del enoturismo", centrado en estudios de mercado, destinos, promoción, imagen, identidad, percepción, etc. Son un conjunto de aspectos de gran interés para crear conciencia de un destino y lealtad de marca, así como para servir de base en conocer cómo intervenir, desde un punto de vista turístico, en un entorno empresarial altamente competitivo. Por todo ello, la investigación en comercialización del turismo del vino es un tema bastante recurrente y transversal en una buena parte de la literatura científica.

El cuarto grupo en importancia se refiere al "comportamiento de los enoturistas", es decir, lo relativo a consumo, frecuencia de visitas, motivación, experiencias anteriores, preferencias actuales y futuras, gastos o toma de decisiones. Como en cualquier otro fenómeno turístico, es necesario comprender el comportamiento del consumidor y las características del mercado en particular, apareciendo en este sentido bastantes publicaciones dedicadas a identificar, perfilar y segmentar a los turistas del vino.

Por último, y para completar la relación de las publicaciones existentes en la base de datos CIRET, hay que destacar las referidas a regiones, modelos, políticas, asociaciones y cooperación en materia de enoturismo. Es decir, algo parecido a lo que se podría denominar como "sistemas enoturísticos". Son temas globales e integradores que facilitan comprender muchos problemas teóricos y prácticos vinculados a esta actividad turística, razón por la cual el número de publicaciones en este campo ha crecido de forma significativa en los últimos tiempos.

También es importante destacar que muchas de las investigaciones publicadas en Australia, Nueva Zelanda, Estados Unidos, Canadá y Suráfrica prácticamente no hacen referencia a los aspectos temáticos del primer grupo, centrados en lo más específico de cultura y patrimonio. Esto constituye una diferencia notable con respecto a lo publicado en Europa. Pero lejos de ser una limitación puede interpretarse como una oportunidad de profundización científica que ampliaría el análisis de lo ya realizado en los países del Nuevo Mundo.

\subsection{Algunos objetivos específicos de investigación}

Una gran parte de la literatura científica se ha dedicado a establecer un perfil determinado del turista del vino. A partir de algunos perfiles propuestos por algunos autores (Mitchell, Hall y McIntonsh, 2000; Charters y Ali-Knight, 2002; Hall y Mitchell, 2008), Pratt (2014) identifica cuatro tipos diferentes de enoturista que resultan muy útiles para comprender el comportamiento de la demanda. Estos perfiles son los siguientes: (i) el amante del vino (the wine lover); (ii) el turista interesado por el vino (the wine interested tourist); (iii) el turista con curiosidad por el vino (the wine courious tourist); y (iv) el enoturista desinteresado (the desinterested wine tourist).

Entre las cuatro categorías existen notables diferencias en relación con los atributos percibidos de una región vitivinícola, la satisfacción y las actitudes hacia las regiones vitivinícolas y las futuras intenciones de visitar alguna de ellas y sus bodegas. 
Las dos primeras categorías consideran que la experiencia enológica es el factor más importante para la visita. Los siguientes factores serían la región en sí misma, el ambiente rural apacible y la belleza del paisaje. Son, de algún modo, las dos categorías más especializadas de enoturistas. La del "turista con curiosidad por el vino" presenta un alto potencial para desarrollar la transición hacia la del "turista interesado por el vino". El ambiente rural y el paisaje son, en este caso, factores determinantes y no tanto la experiencia enológica. El "enoturista desinteresado" no manifiesta mucho interés en conocer a fondo el mundo de vino y la visita a la bodega prácticamente se convierte en una alternativa recreativa de consumo del vino en cualquier local urbano. En general, este grupo presenta las actitudes menos positivas de las cuatro categorías establecidas.

Otro objetivo específico de investigación, enlazando con el propósito final de estudio en este artículo, es el del alcance de las redes y plataformas digitales en la difusión del turismo enológico. Es una temática poco desarrollada aún en relación con esta actividad turística, aunque más ampliamente analizada en otros turismos.

Algunos autores destacan las ventajas de la información online, tanto para los visitantes como para los bodegueros, desempeñando un papel vital (MacCannell, 2002; Richardson, 2002; Murphy, 2006). La primera ventaja, y más evidente, es que las bodegas ganan en competitividad, proporcionando al cliente un rápido acceso a la información. Además, facilita el consumo del vino y se estimulan las visitas. Las páginas web suelen estar bien diseñadas y son muy atractivas, de forma que agilicen la relación con el potencial cliente y promuevan las ventas. Y a nivel turístico se resalta, en las investigaciones que han estudiado este tema, que las plataformas digitales permiten incrementar el negocio del turismo enológico. De hecho, la promoción a través de internet es clave para las bodegas porque frecuentemente el primer contacto del consumidor con las empresas vitivinícolas se hace en la red.

El enoturismo es una rama turística de especial interés para numerosas comarcas y regiones. Por esta razón, su promoción a través de Internet se ha convertido en una herramienta estratégica de gran utilidad para las bodegas y Denominaciones de Origen (D.O.). La búsqueda de nuevos visitantes y de una mayor competitividad ha llevado a las bodegas a colonizar la red de redes y crear, con estrictos criterios de calidad, sus propios sitios web, y con ello, un lenguaje determinado que permita captar la atención de públicos de estratos sociales muy diversos (Sánchez Barbero, 2010). Además, es interesante ver el papel que adquiere la venta del vino a través de las tiendas online de las páginas webs de las propias bodegas, lo que incrementa su accesibilidad, para lo que es necesario su traducción en diversos idiomas (Cuéllar Lázaro, 2006). Estas estrategias de marketing han centrado algunas investigaciones en España, estudiando el alcance del impacto de la información que se comunica a través de los medios digitales (Matellanes, 2012; Camprubí y Galí, 2015).

\section{MÉTODO Y OBJETIVOS DE ANÁLISIS}

El trabajo que se presenta se centra en el conjunto de 631 bodegas que están inscritas en los trece Consejos Reguladores de las D.O. de Castilla y León a 31 de julio de 2018, y que conforman una potente industria vitivinícola regional, en especial, en las llanuras centrales del río Duero. 
En primer lugar se ha seleccionado el tema de estudio a trabajar, el papel que tienen las páginas web y las redes sociales a la hora de visibilizar las bodegas, en especial en el tema del enoturismo, pues, en la mayoría de los casos, es necesario tener reserva previa para poder visitarlas.

Seleccionado el tema de trabajo se procede a recopilar información relacionada con la materia de estudio procedente de documentos oficiales, artículos científicos y páginas web de organismos públicos y privados que nos ha permitido configurar el marco teórico de este trabajo. A todas estas fuentes, hay que añadir el valor que adquiere el trabajo de campo realizado, entrevistas de carácter cualitativo a bodegueros y viticultores, y visitas a bodegas, que contribuyen a apoyar parte del análisis de esta investigación.

El estudio se ha realizado a través del análisis de las 631 bodegas, pero en especial de las 496 que tienen página web $(78,61 \%)$. Se ha accedido a su sitio web con el objetivo de extraer información relevante para el desarrollo de la investigación. Para poder comparar los datos entre unas comarcas vitivinícolas y otras y, posteriormente poder dar una visión global de la situación en Castilla y León, se ha realizado una búsqueda de información que pretende responder a una serie de preguntas claves, tales como emplazamiento de la bodega, denominación de origen a la que pertenece, idiomas disponibles en la página web, redes sociales que tienen o si ofertan enoturismo. En este último, y en el caso de que la respuesta fuese afirmativa, qué tipo de productos y qué actividades.

Una vez que se han obtenido todos los datos se ha procedido a sistematizarlos y a analizarlos para poder trabajar con ellos ante la importante cantidad de información obtenida en esta parte de la investigación. Para ello se han estudiado en profundidad las respuestas obtenidas a nivel de D.O. para proceder a comparar unos espacios con otros y obtener, a manera de resultado final, la situación global a nivel regional.

También se han utilizado los datos de la superficie de viñedo de Castilla y León, desagregando la información por provincias, entre 1990 y 2016, los cuales han sido obtenidos del portal web de estadística de la Consejería de Agricultura y Ganadería de la Junta de Castilla y León. Con toda la información recopilada de los distintos organismos consultados, así como de los Consejos Reguladores, se ha procedido a la elaboración de gráficos, tablas y mapas como soporte visual con el que poder explicar y profundizar en la temática de análisis ya expuesta.

En este trabajo se pretende ver el papel que adquiere para las bodegas la existencia de las páginas web y, más recientemente, de las redes sociales, en el mundo vitivinícola, pero en concreto en relación con el turismo enológico en Castilla y León, uno de los pilares fundamentales en el actual desarrollo rural.

En total hay trece comarcas vitivinícolas (Figura 1) que cuentan con la mención de D.O., una cifra que muestra el papel tan relevante que juega la producción de vinos de calidad en la región. Las D.O. han contribuido a la comercialización y al conocimiento de los vinos y se han convertido, quizá sin pretenderlo inicialmente, en un pilar básico para la práctica del enoturismo. Todo ello aprovechando las sinergias generadas por la existencia de redes conjuntas y compartidas entre las distintas bodegas, ahorrando costes y esfuerzos en muchos casos, sobre todo en las bodegas menos dimensionadas. 


\section{Figura 1 \\ LOCALIZACIÓN DE LAS COMARCAS VITIVINÍCOLAS DE CASTILLA Y LEÓN}

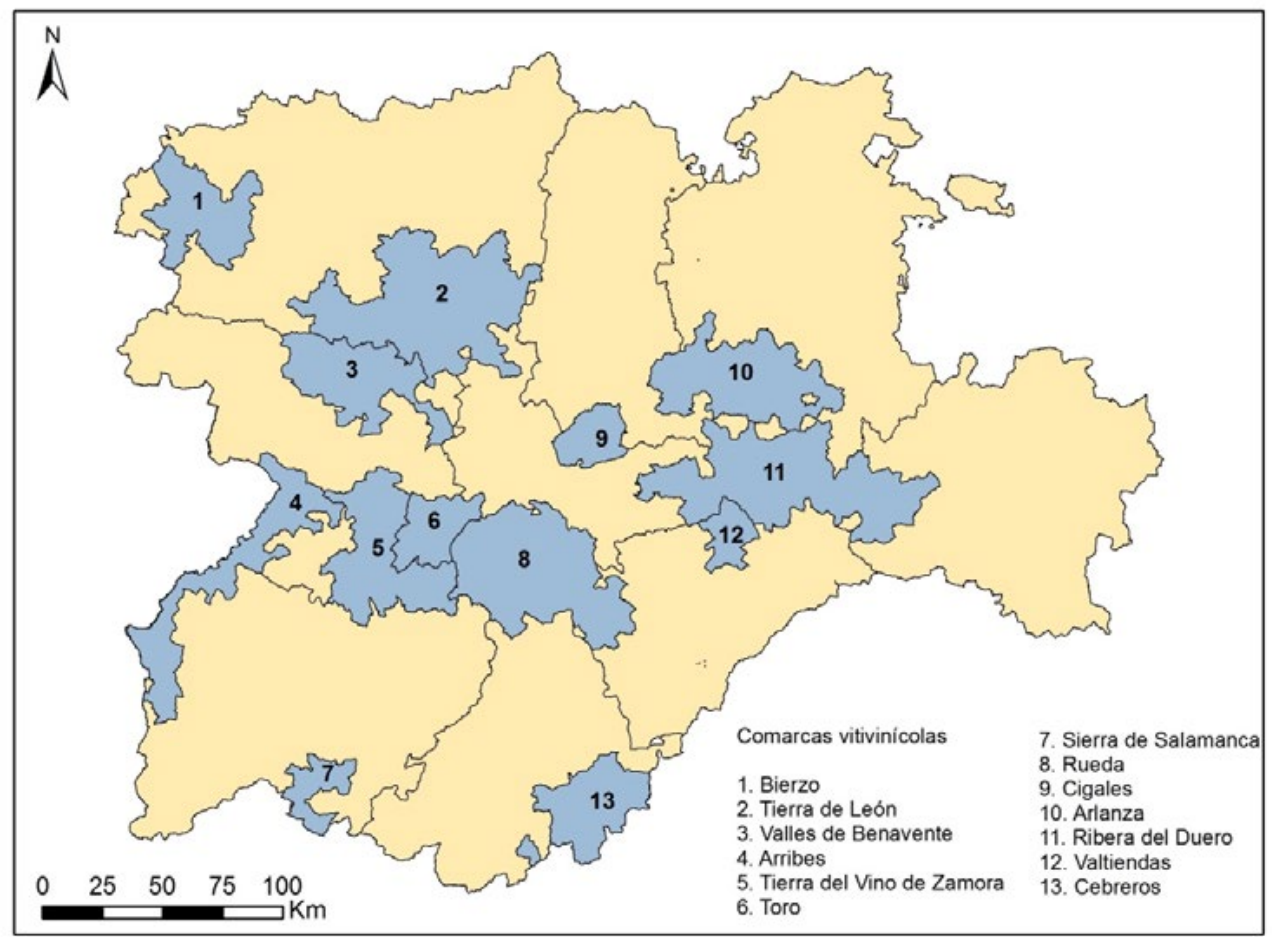

Fuente: Reglamentos de los Consejos Reguladores de las D.O. Elaboración propia.

La investigación se centra en analizar cuáles son las bodegas que cuentan con páginas web y cuáles no, y dentro de ello, aquéllas que ofertan la posibilidad de realizar actividades enoturísticas. A su vez, se van analizar determinados aspectos claves de su configuración como son el idioma, las redes sociales, las actividades que desarrollan y sus instalaciones. Todo ello son aspectos esenciales, desde el punto de vista de los objetivos de análisis propuestos en la investigación, para el funcionamiento de esta actividad económica. El estudio permitirá ver las diferencias existentes entre unos espacios productores y otros.

Algunas de las D.O. como Sierra de Salamanca, Cebreros, Valles de Benavente o Valtiendas, son espacios muy pequeños y poco significativos debido a la escasa superficie de viñedo existente y, como consecuencia, al pequeño número de bodegas (entre cuatro y diez). Su representatividad es muy reducida o casi insignificante, aunque aparecen recogidas en los mapas y figuras elaboradas como forma de completar y comparar mejor la situación real del sector en Castilla y León. Sin embargo, por la alta probabilidad de que introduzcan distorsiones en la muestra, la parte principal de la investigación se centra exclusivamente en las seis principales D.O. regionales como son Ribera de Duero, Rueda, Bierzo, Toro, Cigales y Tierra de León. En su conjunto agrupan prácticamente el $90 \%$ de 
todas las bodegas, y son los espacios más significativos y con mayor peso vitivinícola de la región.

\section{BODEGAS Y VIÑEDOS: LAS BASES DEL ENOTURISMO EN CASTILLA Y LEÓN}

Desde un punto de vista geográfico, la distribución de la superficie de viñedo de Castilla y León se localiza a lo largo de la ribera del río Duero y de sus principales afluentes, como el Pisuerga, el Arlanza o el Esla. Se sitúan a una altitud media comprendida entre los 600 y los 900 metros y constituyen un conjunto de comarcas vitivinícolas de larga tradición que, con el paso de los años, han logrado constituirse como D.O., con las ventajas comerciales y de proyección de imagen que eso representa en el presente y para el futuro.

Además del viñedo de estas comarcas, hay que sumar el resto de superficie vitivinícola regional que no se encuentra inscrita en ninguna D.O. En total, entre viñedo dentro y fuera de D.O., en el año 2016, esa cifra ascendía a 75.439 hectáreas, repartidas entre las nueve provincias, pero con mayor peso las de Valladolid (30,9\%), Burgos $(23,3 \%)$ y Zamora (16,3\%). En total, estas tres provincias concentran el 70,5\% de la superficie total de viñedos de Castilla y León (Tabla 3).

\section{Tabla 3}

EVOLUCIÓN DE LA SUPERFICIE DE VIÑEDO POR PROVINCIAS EN CASTILLA Y LEÓN

\begin{tabular}{|c|c|c|c|c|c|c|c|}
\hline PROVINCIA & $\mathbf{1 9 9 0}$ & $\mathbf{1 9 9 5}$ & $\mathbf{2 0 0 0}$ & $\mathbf{2 0 0 5}$ & $\mathbf{2 0 1 0}$ & $\mathbf{2 0 1 6}$ & $\mathbf{1 9 9 0 - 2 0 1 6}$ \\
\hline Ávila & 6.000 & 6.972 & 4.674 & 3.553 & 4.263 & 4.239 & $\mathbf{- 1 . 7 6 1}$ \\
\hline Burgos & 11.090 & 12.536 & 13.744 & 17.665 & 16.177 & 17.593 & $\mathbf{6 . 5 0 3}$ \\
\hline León & 17.200 & 15.736 & 15.716 & 12.500 & 11.944 & 11.621 & $\mathbf{- 5 . 5 7 9}$ \\
\hline Palencia & 940 & 740 & 636 & 609 & 580 & 518 & $\mathbf{- 4 2 2}$ \\
\hline Salamanca & 6.302 & 3.749 & 3.712 & 2.632 & 2.220 & 2.710 & $\mathbf{- 3 . 5 9 2}$ \\
\hline Segovia & 2.234 & 2.029 & 1.863 & 1.341 & 1.653 & 1.793 & $\mathbf{- 4 4 1}$ \\
\hline Soria & 1.195 & 1.100 & 1.100 & 1.417 & 1.425 & 1.383 & $\mathbf{1 8 8}$ \\
\hline Valladolid & 11.607 & 13.167 & 14.207 & 18.515 & 21.431 & 23.312 & $\mathbf{1 1 . 7 0 5}$ \\
\hline Zamora & 14.649 & 14.236 & 13.823 & 14.444 & 13.240 & 12.270 & $\mathbf{- 2 . 3 7 9}$ \\
\hline Castilla y León & $\mathbf{7 1 . 2 1 7}$ & $\mathbf{7 0 . 2 6 5}$ & $\mathbf{6 9 . 4 7 5}$ & $\mathbf{7 2 . 6 7 6}$ & $\mathbf{7 2 . 9 3 3}$ & $\mathbf{7 5 . 4 3 9}$ & $\mathbf{4 . 2 2 2}$ \\
\hline
\end{tabular}

Fuente: Consejería de Agricultura de la Junta de Castilla y León. Elaboración propia.

Si se tiene en cuenta el periodo 1990-2016 la superficie regional de viñedo se ha incrementado tan solo en 4.222 hectáreas. Esta cifra contrasta con el fuerte crecimiento 
experimentado en la provincia de Valladolid, en especial gracias a la expansión de las D.O. Ribera del Duero y Rueda, con un aumento de 11.705 hectáreas. En Burgos sucede prácticamente lo mismo, con 6.503 nuevas hectáreas como consecuencia del incremento registrado en la D.O. Ribera del Duero, lo que afecta también parcialmente a la provincia de Soria. En el resto de provincias hay una pérdida variable de superficie al no tener D.O. tan potentes como las mencionadas anteriormente. Espacios donde se han producido importantes inversiones para la plantación de viñedos y para la construcción de nuevas bodegas y ampliación de las existentes.

Estas modificaciones permiten afirmar que lo que ha tenido lugar en Castilla y León en las tres últimas décadas ha sido una redistribución de la superficie del viñedo, reduciéndose en las comarcas vitivinícolas menos rentables como Tierra de Campos, Tierra de Pinares, Cebreros, Arribes del Duero o la Tierra de León (algunas de las cuales no han tenido una figura de protección hasta comienzos del siglo XXI) y concentrándose principalmente en aquellas más dinámicas, como Rueda, Ribera del Duero y Toro (Molinero Hernando, 2011; Fernández Portela, 2014).

Respecto al número de bodegas, el total de las inscritas en los respectivos Consejos Reguladores de las D.O. se eleva a un total de 631, distribuidas de forma desigual por el territorio. Valladolid, con el 33,93\% de total, es la que presenta el mayor número, seguida de Burgos con el 28,84\%. Entre las dos agrupan más del 60\% del total, principalmente gracias al importante grupo que aporta la D.O. Ribera del Duero. En el caso concreto de Valladolid hay que añadir, además, las de Rueda y Cigales, y en Burgos la D.O. Arlanza. En todos estos casos, el sector ha sido capaz de atraer en los últimos años capitales tanto de origen familiar como de grandes empresas, lo que ha impulsado y dinamizado la economía local y regional en su conjunto. Y, como factor añadido, hay que señalar que estos capitales han aprovechado a su vez la coyuntura económica favorable que vive la vitivinicultura y, en concreto, el reconocimiento nacional e internacional de los vinos elaborados en Ribera del Duero y Rueda. La provincia de León concentra, aunque en proporciones inferiores a las dos provincias mencionadas, un significativo $17,75 \%$ del total como consecuencia de las bodegas de la D.O. Bierzo y, en menor medida, de la de Tierra de León.

La mayor parte de las bodegas se encuentran a lo largo de la ribera del río Duero y en sus inmediaciones. Forman casi un corredor continuo que empieza en los límites de la provincia de Soria con Burgos, pasando por Valladolid y continuando por Zamora hasta llegar al encajonamiento del Duero en las penillanuras zamoranas-salmantinas en la frontera con Portugal (Figura 2). En este corredor del vino, la D.O. Ribera del Duero, con 283 bodegas y el $45 \%$ del total, es la que concentra el mayor número de ellas, destacando a continuación las de Rueda y Toro. Ajeno a la dinámica de este eje vitivinícola del Duero destaca la D.O. Bierzo, en el extremo noroccidental de la región, bañando sus aguas otro río, el Sil, y con un entorno natural diferente, que permite la producción de uvas de variedades distintas que a su vez permiten elaborar vinos con otros matices y sabores.

Viñedos y bodegas, y en concreto el vino, se constituyen como los pilares esenciales que van a permitir el desarrollo del enoturismo. A ello hay que añadir el resto de potencialidades presentes en el territorio, como la riqueza del patrimonio histórico-artístico con castillos, fortalezas, iglesias, ermitas y el Canal de Castilla, los parajes naturales, la 
gastronomía, las fiestas populares y las dedicadas al vino. En definitiva, un amplio abanico de recursos que complementan este tipo de turismo y convierten a Castilla y León en uno de los destinos de interior más demandados, y en uno de los principales centros receptores de enoturistas del país (ACEVIN ${ }^{3}$ )

Para el correcto desarrollo de este tipo de turismo es necesario disponer de información sobre la bodega a visitar y realizar, en la mayor parte de los casos, una reserva previa por teléfono o por correo electrónico, información que suele recogerse en las páginas web. Es en este momento donde entra en juego el papel que adquieren las nuevas tecnologías de la información y la comunicación (TIC), pues son herramientas imprescindibles de gestión, promoción y difusión para el desarrollo de cualquier tipo de actividad turística en las bodegas y viñedos y, por extensión, en las comunidades locales.

\section{Figura 2 \\ DISTRIBUCIÓN DE LAS BODEGAS EN CASTILLA Y LEÓN EN 2018}

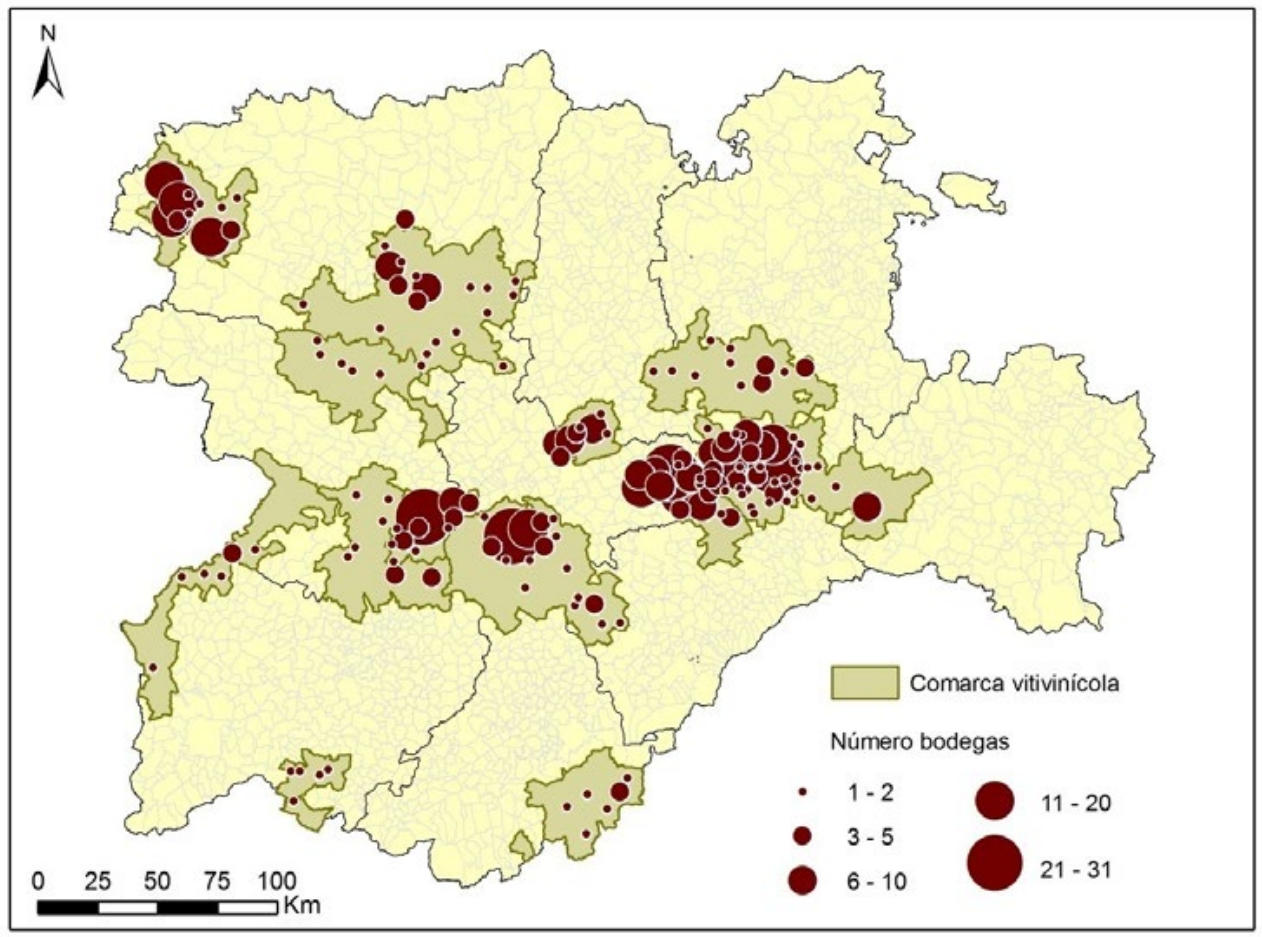

Fuente: Consejos Reguladores de las D.O. Elaboración propia.

3 Informes de visitantes a bodegas asociadas a las Rutas de Vino de España en 2013, 2014, 2015, 2016 y 2017 . 


\section{PÁGINAS WEB Y REDES SOCIALES EN EL DESARROLLO DEL TURISMO DEL VINO}

La página web y, más recientemente, las redes sociales de una empresa se han convertido en un escaparate al mundo que trasciende los estrechos márgenes del lugar donde se localiza. Permiten mostrar el producto que elaboran o a lo que se dedican. En el caso de las bodegas, debido a la fuerte competencia en el sector, dan a conocer sus vinos en prácticamente cualquier rincón del planeta y comercializarlos, pues algunas cuentan con tienda online.

La presencia en las plataformas digitales es esencial para el desarrollo del enoturismo. En la mayoría de las bodegas es necesaria la reserva previa para poder visitar sus instalaciones. Además, y para los intereses y objetivos de esta investigación, permite comprobar el tipo de visitas que realizan, las actividades que promueven y si cuentan con servicios como hoteles, restaurantes, museos o tiendas. De las 631 bodegas existentes, casi el 80\% $(78,61 \%)$ cuenta con una página web, una cifra elevada que pone de manifiesto el interés por convertirse en bodegas que abarquen un ámbito más allá del estrictamente local (Tabla 4).

Sin embargo hay diferencias entre comarcas. Van a ser las D.O. más dinámicas y las que más están creciendo en la actualidad, las que cuentan con un mayor número de bodegas con página web. Es el caso de Rueda y Ribera del Duero, con un 92,54 y $84,81 \%$, respectivamente. Estos dos espacios, en especial Rueda, son los que están concentrando la mayor parte de la inversión en el sector con nuevas plantaciones, la llegada de grandes grupos empresariales y con la construcción de modernas instalaciones (Fernández Portela, 2017), constituyéndose como las dos áreas vitivinícolas más demandadas para realizar turismo enológico en Castilla y León, y en el caso de la Ribera del Duero como un referente enoturístico a nivel nacional.

\section{Tabla 4 \\ DISTRIBUCIÓN POR COMARCAS VITIVINÍCOLAS DE BODEGAS CON Y SIN PÁGINA WEB EN 2018}

\begin{tabular}{|l|c|c|c|c|c|}
\hline D.O. & $\mathbf{N}^{\mathbf{0}}$ Bodegas & $\begin{array}{c}\text { Con página } \\
\text { web }\end{array}$ & $\begin{array}{c}\text { \% con } \\
\text { página }\end{array}$ & $\begin{array}{c}\text { Sin página } \\
\text { web }\end{array}$ & $\begin{array}{c}\text { \% sin } \\
\text { página }\end{array}$ \\
\hline Cigales & 34 & 25 & 73,53 & 9 & 26,47 \\
\hline Rueda & 67 & 62 & 92,54 & 5 & 7,46 \\
\hline Toro & 59 & 45 & 76,27 & 14 & 23,73 \\
\hline Tierra de León & 41 & 25 & 60,98 & 16 & 39,02 \\
\hline Arlanza & 23 & 14 & 60,87 & 9 & 39,13 \\
\hline $\begin{array}{l}\text { Tierra del Vino de } \\
\text { Zamora }\end{array}$ & 11 & 6 & 54,55 & 5 & 45,45 \\
\hline Arribes & 12 & 9 & 75,00 & 3 & 25,00 \\
\hline
\end{tabular}




\begin{tabular}{|l|c|c|c|c|c|}
\hline D.0. & $\mathbf{N}^{\mathbf{0}}$ Bodegas & $\begin{array}{c}\text { Con página } \\
\text { web }\end{array}$ & $\begin{array}{c}\text { \% con } \\
\text { página }\end{array}$ & $\begin{array}{c}\text { Sin página } \\
\text { web }\end{array}$ & $\begin{array}{c}\text { \% sin } \\
\text { página }\end{array}$ \\
\hline Bierzo & 74 & 54 & 72,97 & 20 & 27,03 \\
\hline Valles de Benavente & 6 & 3 & 50,00 & 3 & 50,00 \\
\hline Sierra de Salamanca & 5 & 4 & 80,00 & 1 & 20,00 \\
\hline Valtiendas & 6 & 5 & 83,33 & 1 & 16,67 \\
\hline Cebreros & 10 & 4 & 40,00 & 6 & 60,00 \\
\hline Ribera del Duero & 283 & 240 & 84,81 & 43 & 15,19 \\
\hline TOTAL & $\mathbf{6 3 1}$ & $\mathbf{4 9 6}$ & $\mathbf{7 8 , 6 1}$ & $\mathbf{1 3 5}$ & $\mathbf{2 1 , 3 9}$ \\
\hline
\end{tabular}

Fuente: Consejos Reguladores. Elaboración propia.

Según datos de ACEVIN, en el año 2013 las bodegas pertenecientes a la Ruta del Vino Ribera del Duero recibieron 179.938 visitantes, incrementándose en 2016 a 351.389 ; en el caso de la D.O. Rueda, la evolución fue, en el mismo periodo, de 20.440 a 29.665 visitantes ${ }^{4}$. El resto de las grandes D.O. como Bierzo, Toro o Cigales se encuentran un poco por debajo de la media regional, pero superior al 70\%, unas cifras algo más bajas debido a la menor presencia de grandes empresas en estos territorios. Sin embargo, el que una bodega tenga página web no significa que oferte actividades vinculadas con el turismo enológico, pues muchas de ellas no se dedican a este nuevo sector y en sus instalaciones solo elaboran vino. De las 496 bodegas que cuentan con ella, tan solo 157, el 31,65\%, ofertan la posibilidad de hacer enoturismo (Figura 3).

Por encima de este porcentaje se encuentran las D.O. Rueda, Bierzo, Cigales y Arlanza, también Sierra de Salamanca, estos cinco territorios cuentan con su Ruta del Vino correspondiente, asociaciones que pretenden impulsar el enoturismo de una comarca vitivinícola agrupando a bodegas, restaurantes, alojamientos, etc. Para ello se organizan actividades y se diseñan programas turísticos y culturales que fomentan la llegada de personas con la idea de potenciar esta tipología turística. Todo ello deja ver una relación entre los espacios que ofertan turismo del vino con aquellos que se encuentran dentro de una de estas rutas, a pesar de ser entidades de reciente creación (Bierzo de 2011 y Sierra de Salamanca y Arlanza, 2017). En el caso de la D.O. Ribera del Duero (30,42\%), también con Ruta del Vino, la primera de la región, con un mayor camino recorrido y una de las que mayor número de visitantes tienen en toda España, se encuentra ligeramente por debajo de la media regional. Ribera del Duero parte de una situación diferente al resto, pues concentra alrededor de la mitad de las bodegas del total de la muestra, y presentan casuísticas muy dispares. En este caso van a ser las empresas más grandes las que ofertan una amplia variedad enoturística, con personal cualificado en turismo y comunicación. A pesar de todo, son más de setenta las bodegas que organizan visitas y realizan actividades que tienen como elemento clave el vino.

4 Hay que tener en cuenta que no todas las bodegas forman parte de las Rutas del Vino, por lo que el número de visitantes de las bodegas es mayor. 


\section{Figura 3 \\ BODEGAS CON PÁGINA WEB QUE OFERTAN ENOTURISMO}

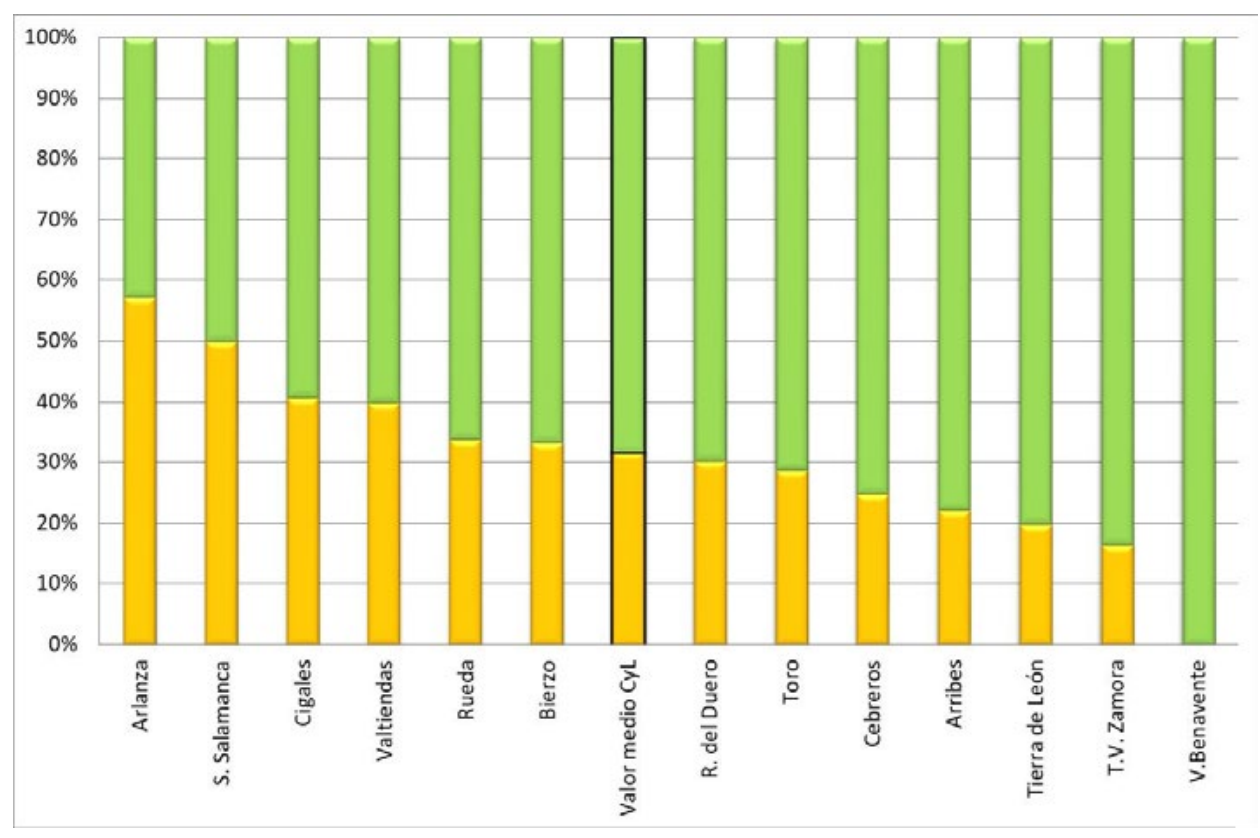

Fuente: Páginas web de las bodegas de la muestra. Elaboración propia.

La actividad más habitual que ofertan las bodegas en sus páginas web es la visita a sus instalaciones de elaboración del vino y, en ocasiones, a los viñedos. Esta actividad consiste en el recorrido del complejo mientras se explica el proceso de recepción de la uva y de elaboración del vino. Al finalizar suele terminar con una cata de los vinos que elaboran. En la últimas dos décadas han tenido lugar inversiones orientadas a la adaptación de estas instalaciones para recibir visitantes, creando nuevos espacios o adaptando los existentes para el desarrollo de nuevas actividades. La fuerte competencia en el sector obliga a innovar y presentar propuestas atrayentes para captar la atención de los clientes.

En un principio la visita era la única actividad que se realizaba, pero con el paso de los años, y debido al creciente interés por parte de los turistas, se han incluido otras actividades y servicios. Se organizan cursos de cata y maridaje, jornadas de divulgación o congresos de investigación. La mayoría poseen una pequeña tienda en la que se pueden adquirir los vinos que elaboran, así como otros productos agroalimentarios de Castilla y León y otros derivados de la uva como pueden ser cosméticos de belleza, champús, mermeladas, etc. A esto hay que sumar la incorporación de restaurantes, alojamientos, museos y spa. De las 157 páginas web analizadas de bodegas que ofertan enoturismo, 50 poseen restaurantes, 23 hoteles, 6 museos y 4 cuentan con SPA. La mayor parte de 
estas bodegas se corresponden con la D.O. Ribera del Duero, que es el foco principal del turismo del vino de la región, tanto por volumen final de visitas, como por actividades realizadas. Estas empresas se están orientando al enoturismo como estrategia empresarial de diversificación económica y promoción exterior de su propia imagen.

También es importante la presencia de información en otros idiomas en las páginas web. Esto es fundamental para poder comercializar los vinos en el exterior y su proyección internacional, así como para la recepción de visitantes extranjeros. De las 496 bodegas que tienen página web, el 66,73\% la tienen traducida a dos o más idiomas, mientras que el $33,27 \%$ tan solo está en español. Hay que mencionar que muchas de las páginas existentes son muy simples, se elaboraron en su día y, según se ha podido comprobar al visitarlas, nunca se han modificado para actualizar sus contenidos. Reflejan información muy genérica de las bodegas y de los vinos y, en general, se encuentran solo en español. Suelen ser bodegas pequeñas y familiares con una producción de menos de 300.000 litros.

A pesar de ello, el 66,73\% de las bodegas con página web tienen dos o más idiomas, lo que refleja que son empresas que exportan vino al exterior o pueden tener la intención de hacerlo. Lo más normal es que esté en español y otro idioma $(42,94 \%)$, con tres idiomas el $13,10 \%$, cuatro idiomas el 6,45\% y cinco o más idiomas el 4,23\%. En este último caso, suelen ser páginas que tienen traducción simultánea a numerosas lenguas.

La traducción de la información de estos sitios web depende de los vínculos que tengan las bodegas con determinados países. La mayor parte de ellas cuentan con una traducción al inglés, pues es el idioma clave en el ámbito de los negocios y de esta forma se puede llegar a un mercado de clientes más amplio. Un factor que va a influir en el idioma es el origen de las empresas y su presencia en otras comarcas vitivinícolas nacionales e internacionales. En estos casos, además del español, tendrán la traducción a su lengua de origen y a aquella propia del lugar donde se ubiquen.

El idioma más común es el inglés, pues de las 331 bodegas con dos idiomas, 319 están en inglés, es decir, prácticamente todas las bodegas con dos o más idiomas. En segundo lugar, aunque muy alejado, se encuentran las páginas con traducciones al alemán, un mercado importante de consumidores de vinos castellanoleoneses, y luego en francés. También algunas de ellas cuentan con traducciones al chino y ruso, (alrededor del 10 y del $4 \%$ de las bodegas en la actualidad) lo que indica el interés por parte de clientes procedentes de estos países (Figura 4). Una cuestión positiva, pues ambos países cuentan con una importante población y un nicho de mercado clave para la industria vitivinícola nacional y, en especial de Castilla y León, que tiene una fuerte competencia en este sector con la difusión de vino procedente de otros territorios nacionales, además de los tradicionales europeos de Francia e Italia, y de otros países como Chile, Argentina, Australia o Estados Unidos.

Complementando a las páginas web, en los últimos años se ha expandido el uso y manejo por parte de las bodegas y consumidores de las redes sociales, una forma de comunicación clave en la sociedad, no solo por parte de los jóvenes, sino también de los adultos. Mensajes cortos y directos, el uso de fotografías, promociones, concursos, premios, experiencias vividas por los visitantes, etc., en definitiva, lo que se pretende es captar la atención de posibles consumidores. 


\section{Figura 4 \\ IDIOMAS MÁS FRECUENTES EN LAS PÁGINAS WEB}

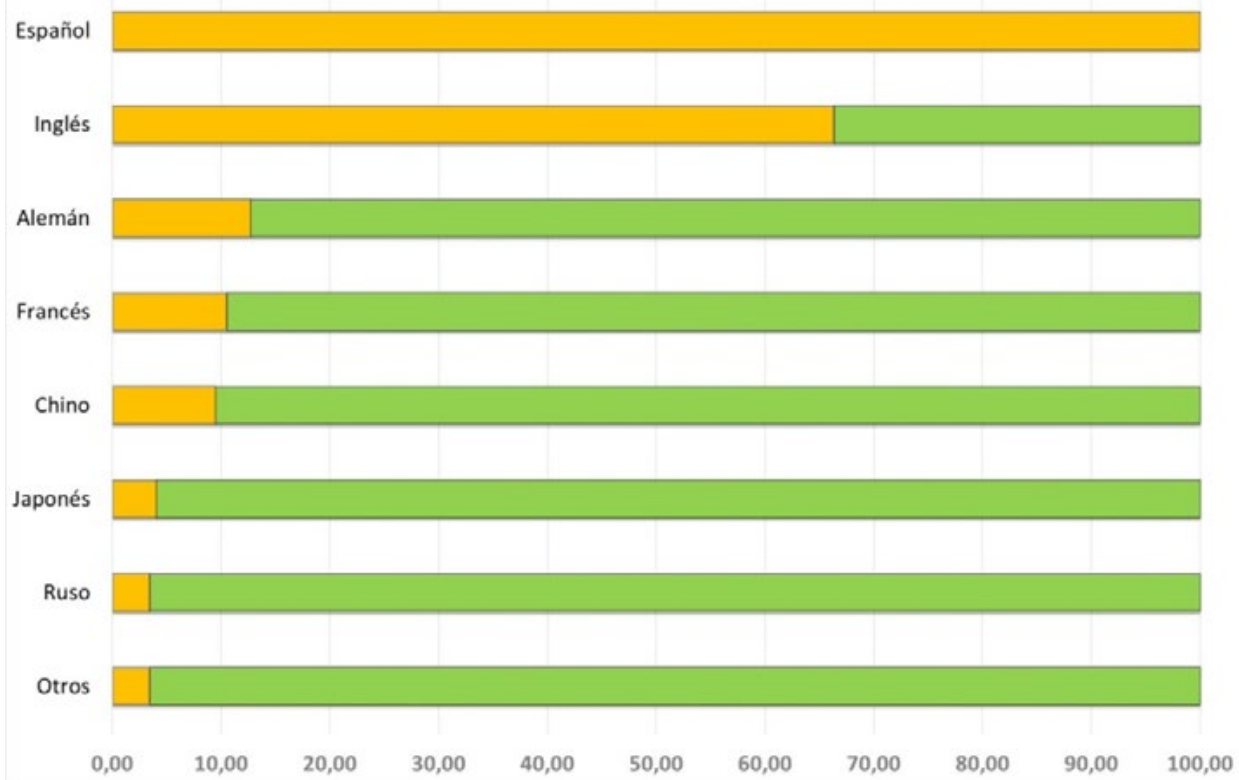

Fuente: Páginas web de las bodegas de la muestra. Elaboración propia.

La revolución que se está viviendo en la actualidad con las redes sociales ha despertado el interés en el mundo del vino que también ha decidido unirse a ello. Facebook, Twitter, Instagram, Blogger, Youtube, Google+, Linkedin, etc., son algunas de las redes sociales más frecuentes. Algunas bodegas cuentan con personal especializado en comunicación, habitualmente las empresas más grandes, que se ocupan de temas de promoción y de publicidad y que te cuentan, casi hora tras hora, lo que sucede en la empresa. El consumo de publicidad a través de este tipo de redes es importante, por lo que es una buena forma de darse a conocer entre el público y vender el producto, en especial entre los más jóvenes, uno de los objetivos de algunas comarcas vitivinícolas como Cigales y Rueda. Se están lanzando mensajes y campañas publicitarias destinadas a este colectivo de población, sin descuidar otros mercados que se encuentran más consolidados. Realizan vídeos, anuncios televisivos, publicidad en prensa escrita y digital. Los viñedos y las bodegas son escenarios de cortos de cine, de películas y de sesiones de fotografía, patrocinan eventos musicales, cinematográficos o deportivos. En definitiva, pretenden diferenciar sus respectivos productos en un mercado con una competencia cada vez mayor y captar un potencial mercado, el de los jóvenes.

Según el estudio realizado, el $65,32 \%$ de las bodegas que tienen página web posee al menos una red social, frente al $34,68 \%$ que no tiene redes sociales. Lo habitual es que 
tengan más de una, así pues, el 12,96\% posee una red, el 32,10\% dos, el 26,54\% cuentan con tres redes sociales, el 16,36\% con cuatro y el $12,04 \%$ con cinco o más redes sociales. Las redes sociales más extendidas entre los consumidores son Facebook, presente en casi todas las bodegas que cuentan con esta herramienta y Twitter con alrededor del $80 \%$ (Figura 5). Estas dos son las más expandidas entre la población y por lo tanto son los principales canales de comunicación entre las bodegas, sus consumidores habituales y los posibles futuros clientes. Redes sociales en las que se informa de promociones, de eventos y otras actividades por parte de las bodegas, pero que al mismo tiempo, los visitantes "cuelgan" en sus respectivos muros las experiencias vividas durante la visita a las instalaciones que sirven de publicidad gratuita para la bodega, pues son fotografías que comparten con sus amigos.

\section{Figura 5 \\ PORCENTAJE DE PÁGINAS WEB CON REDES SOCIALES}

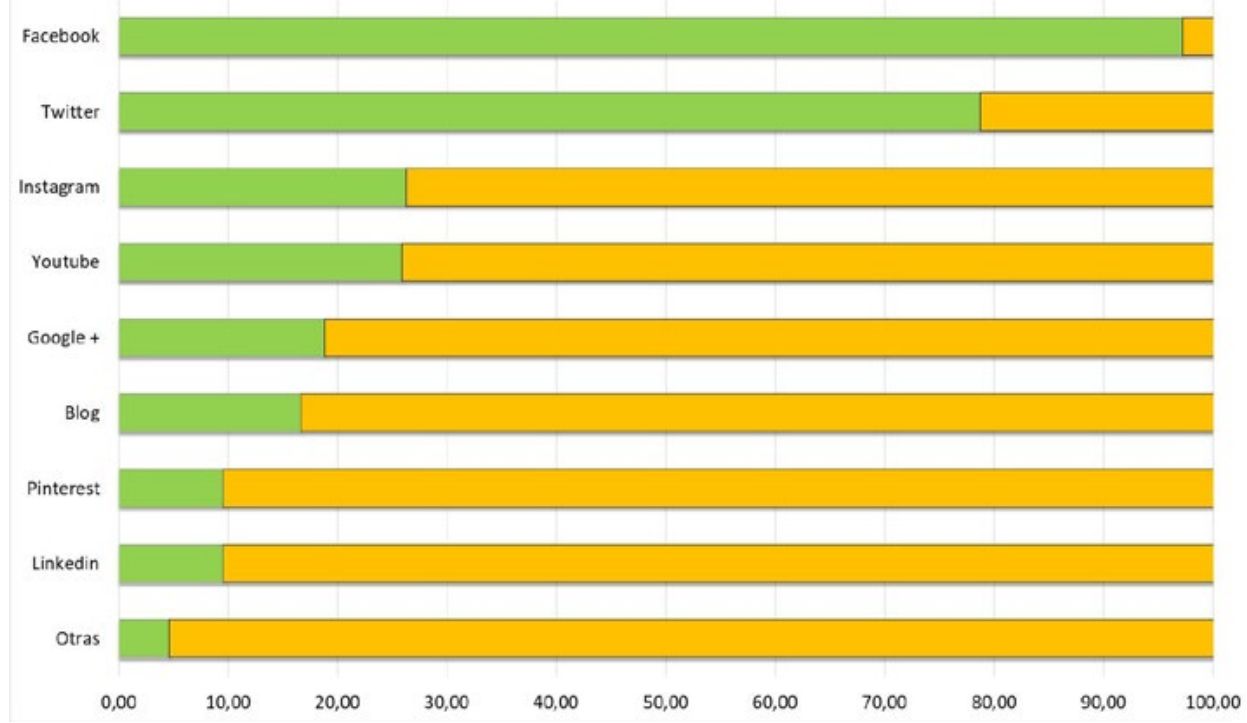

Fuente: Páginas web de las bodegas de la muestra. Elaboración propia.

Por comarcas vitivinícolas, las bodegas de la D.O. Rueda son las que más están integradas en el uso y manejo de las redes sociales con el 87,10\% (Figura 6), pues tanto las bodegas como el Consejo Regulador llevan años realizando una importante campaña de promoción que ha dado lugar a un incremento de la superficie de viñedo, así como del número de bodegas y, asociado a ello, ha tenido lugar la apertura de restaurantes, hoteles y vinotecas entre otros establecimientos relacionados con el vino. Por encima de la media, y dentro del conjunto de grandes D.O., se encuentran Toro y Bierzo, siguiendo una dinámica algo similar a Rueda pero en menor escala. A continuación destaca Ribera del Duero, gracias a la labor de los grupos empresariales de mayor tamaño que han ido colo- 
nizando el valle del río Duero hasta convertirse en los motores reales de un enoturismo cada vez más pujante y reconocido entre la población local de toda la región. Las inversiones en el territorio han sido realizadas por grupos como Protos, Matarromera, Arzuaga o Portia con inversiones millonarios destinadas a la construcción de nuevas bodegas con diseños vanguardistas dentro de la corriente de la enoarquitectura, más atractivas para los turistas, así como otros equipamientos tales como restaurantes, hoteles, spa, museos, etc.

\section{Figura 6 \\ PORCENTAJE DE REDES SOCIALES POR COMARCAS VITIVINÍCOLAS}

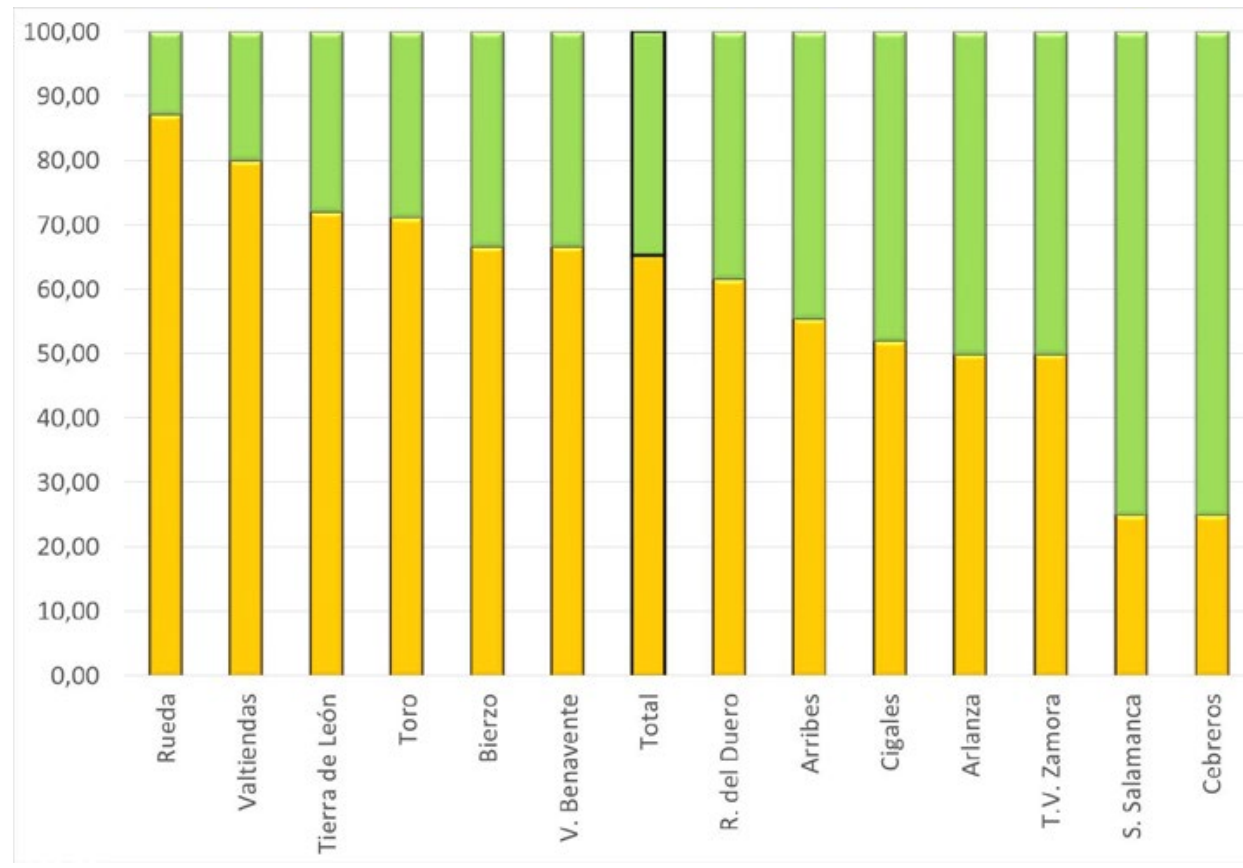

Fuente: Páginas web de las bodegas de la muestra. Elaboración propia.

\section{CONCLUSIONES}

La industria vitivinícola tiene un papel clave en el desarrollo económico del medio rural de Castilla y León. Puede afirmarse que ya se ha convertido en un motor esencial para su revitalización social, como actividad agroindustrial, así como turística, al atraer visitantes y asentando, en algunos casos, nuevos pobladores o manteniendo los existentes, en un espacio caracterizado, a lo largo de las últimas décadas, por ser uno de los vacíos demográficos más importantes de España y de toda la Europa occidental.

Junto a la producción de vino hay que destacar la relevancia que va adquiriendo el turismo enológico como una actividad que gira en torno al mundo de la vid y el vino. Se ha podido comprobar y confirmar que es capaz de atraer a cientos de miles de visitantes 
a las llanuras del Duero principalmente, situándose en torno a los 500.000 enoturistas en 2017, y con perspectivas de seguir aumentando según los estudios de la Asociación de Rutas del Vino. Las diferencias regionales van a ser una de las características claves en el sector, y esto se va a notar en el interés por desarrollar páginas web más novedosas, con mayor información, en diversos idiomas, etc. A pesar del valor tan representativo en el conjunto regional, existe una clara concentración en una comarca vitivinícola. Sin embargo, esto no es del todo malo, pues se está produciendo un efecto de arrastre a otros territorios productores de vino que están incrementando su representatividad.

El $80 \%$ pertenecen a la D.O. Ribera del Duero, la tercera ruta del vino más visitada de toda España solo por detrás de la Ruta del Vino de Jerez y Ruta del Vino de Penedés. El restante $20 \%$ de los enoturistas que llegan a esta tierra pertenecen a las Rutas del Vino de Rueda, Bierzo, Cigales, Arlanza y Sierra de Salamanca (No hay datos disponibles de la Ruta del Vino Arribes que fue creada a finales de 2018 y de la Ruta del Vino Toro en febrero de 2019). A pesar de ello, las rutas del vino de más reciente creación están experimentando un importante crecimiento, y es de esperar que esta cifra siga aumentando año tras año ante la vitalidad constatada actualmente, el reconocimiento logrado y el valor de las instalaciones y de los equipamientos.

Las plataformas digitales se convierten en un medio básico para este tipo de turismo. Las páginas web y las redes sociales son dos potentes instrumentos utilizados en favor del conocimiento de las bodegas y como medio de reserva de visitas y degustaciones. Esto es un hecho importante, pues cada vez está más extendido, lo que permite incrementar su presencia y puede llegar a un público más amplio en cualquier rincón del planeta. En este sentido, el trabajo que han realizado las bodegas de las D.O. de Castilla y León ha sido importante y ha supuesto un gran esfuerzo social y económico para poder adaptarse a las exigencias de los nuevos mercados y a los gustos y formas de compra de los consumidores. Todo esto adquiere mayor relevancia en el territorio, pues es un espacio geográfico que presenta severos problemas estructurales en lo que se refiere a conexión y conectividad.

El acceso a internet y la cobertura de telefonía móvil en algunos territorios de las comarcas vitivinícolas es insuficiente, de mala calidad, e incluso casi inexistente. Estas circunstancias dificultan y, en ocasiones, imposibilitan, el desarrollo correcto de estas actividades económicas en las que cada vez es más frecuente una buena conexión a internet para poder desarrollar este tipo de trabajos. Hay que recordar que numerosas bodegas cuentan con tienda online (alrededor del $40 \%$ del total de la muestra) donde venden sus vinos, y todo el entramado enoturístico se realiza a través de la página web, mediante el uso del correo electrónico, por teléfono o a través de las redes sociales.

Es por ello, que se hace necesaria la actuación por parte de las administraciones públicas, regionales y locales, así como de empresas privadas, para que pongan en marcha iniciativas y actuaciones encaminadas a mejorar el sistema de comunicaciones en las áreas rurales de la región, en aquellas en las que ya existe actividad económica, así como en las que no, pues podrían convertirse en espacios más atractivos para el asentamientos de actividades empresariales.

A pesar de estos inconvenientes, la apuesta por la industria vitivinícola en la región ha sido clara y firme y se ha expandido, principalmente, por todo el valle del Duero y 
por algunos de sus afluentes como el Pisuerga, el Arlanza o el Esla, así como por otros territorios como son los del valle del Sil en El Bierzo, consolidándose como un motor económico y de desarrollo del medio rural.

Tal y como se ha tenido oportunidad de comprobar en este estudio, la presencia de las plataformas digitales en el sector del enoturismo tiene un papel muy significativo, pues se emplean para promocionar las actividades que en ellas se organizan, y todo parece indicar que seguirá incrementándose con el tiempo. Alrededor del $80 \%$ de las bodegas cuentan con página web, una cifra elevada pese a las dificultades que se acaban de comentar, además de la alta representación de la bodega familiar en la estructura económica vitivinícola regional, alrededor del $70 \%$. La página web ha sido el comienzo, pues luego se han adaptado a las nuevas formas de comunicación de los consumidores con la creación de redes sociales. En estas redes se comparten y anuncian informaciones relevantes sobre sus productos, instalaciones y actividades, lo que permite ampliar el mercado, captar y fidelizar nuevos consumidores e incrementar el volumen total de visitantes. Es una nueva forma de publicidad, rápida, más barata, y en muchas ocasiones gratuita, pues los propios visitantes de las bodegas se van a encargar de difundir las experiencias que han vivido con fotografías, comentarios y vídeos que pueden llegar a un público muy amplio.

\section{BIBLIOGRAFÍA}

ALANT, K. y BRUWER, J. (2004): «Wine tourism behavior in the context of a motivational framework for wine regions and cellar doors», Journal of Wine Research, vol. 15 (1), pp. 27-37.

BRUNORI, G. y ROSSI, A. (2000): «Synergy and coherence through collective action: some inlights from wine routes in Tuscany», Sociologia Ruralis (Journal of the European Society for Rural Sociology), vol. 40 (4), pp. 409-423.

CAMPRUBÍ, R. y GALÍ, N. (2015): «An exploratory analysis of wineries websites functionality: the case of the DOQ Priorat route-wineries» Boletín de la Asociación de Geógrafos Españoles, $\mathrm{n}^{\circ}$ 68, pp. 159-176.

CARLSEN, J. (2004): «A review of global wine tourism research», Journal of Wine Research, vol. 15 (1), pp. 5-13.

CARLSEN, J. y CHARTERS, S. (2006): Global Wine Tourism. Research, Management and Marketing. Wallingford, CAB International.

CHARTERS, S. y ALI-KNIGHT, J. (2002): «Who is the wine tourist?, Tourism Management, vol. 23 (3), pp. 311-319.

CUELLAR LAZARO, C. (2006): «Los vinos de la DO Ribera del Duero a través de las traducciones de sus páginas web» en El lenguaje de la vid y el vino y su traducción. Valladolid, Universidad de Valladolid, Secretariado de Publicaciones e Intercambio Editorial, pp 333-346.

DODD, T. (2000): «Influences on cellar door sales and determinants of wine tourism success: results from Texas wineries», en Wine Tourism around the World. Development, Management and Markets. Oxford, Butterworth Heinemann, pp.136-149. 
FERNÁNDEZ PORTELA, J. (2014): La industria del vino y la viticultura en Castilla y León: Su incidencia en el paisaje y en el desarrollo rural, (Tesis Doctoral). Valladolid, Universidad de Valladolid. Disponible en http://uvadoc.uva.es/handle/10324/8502

FERNÁNDEZ PORTELA, J (2017): «La industria vitivinícola de la D.O. Rueda como motor de cambio del territorio», Cuadernos Geográficos de la Universidad de Granada, vol. 56 (3), pp. 292-311.

GETZ, D. (2000): Explore Wine Tourism. Management, Development and Destinations. New York, Cognizant Communication Corporation.

HALL, C. M., SHARPLES, L., CAMBOURNE, B . y MACIONIS, N. (2000): Wine Tourism around the World. Development, Management and Markets. Oxford, Butterworth Heinemann.

HALL, C. M. y MITCHELL, R. (2008): Wine Marketing: a Practical Guide. Oxford, Elsevier Ltd.

HEANEY, L. (2003): «Tapping the barrel, profiling domestic wine tourists, 1998-2001», BTR Tourism Research Report, vol. 5 (1), pp. 39-43.

JENNINGS, G. R. (2001): Tourism Research. Brisbane, John Wiley.

KUNC, M. (2010): «Wine tourism: a review of the Chilean case», International Journal of Tourism Policy, vol. 3 (1), pp. 51-61.

LÓPEZ-GUZMAN, T., RODRÍGUEZ GARCÍA, J. y VIEIRA RODRÍGUEZ, A. (2013): «Revisión de la literatura científica sobre enoturismo en España», Cuadernos de Turismo, $\mathrm{n}^{\circ} 32$, pp. 171-188.

MATELLANES, M. (2012): «Comunicación del turismo del vino en España a través de la web» Razón y Palabra, $\mathrm{n}^{\circ}$ 81. Disponible en https://dialnet.unirioja.es/servlet/artic ulo?codigo $=4751684$ \&orden $=1$ \&info $=$ link

MCCANNELL, D. (2002): «The ego factor in tourism», Journal of Consumer Research, vol. 29 (1), pp. 146-151.

MITCHELL, R. y HALL, C. M. (2006): «Wine tourism research: the state of play», Tourism Review International, vol. 9 (4), pp. 307-332.

MITCHELL, R., HALL, C. M. y MCINTOSH, A. (2000): «Wine tourism and consumer behavior», en Wine Tourism around the World. Development, Management and Markets. Oxford, Butterworth Heinemann, pp. 115-135.

MOLINERO HERNANDO, F. (2011): «Los paisajes del viñedo en Castilla y León: tradición, renovación y consolidación», Polígonos. Revista de Geografía, no 21, pp. 85-117.

MURPHY, J. (2006): «Electronic marketing and wine tourism», en Global Wine Tourism. Research, Management and Marketing. Wallingford, CAB International, pp. 110-122.

PRATT, M. (2014): «Four wine tourist profiles», Academy of Wine Business Research. Proceedings of the $8^{\text {th }}$ International Conference. Geisenheim (Alemania), junio de 2014. Disponible en https://core.ac.uk/download/pdf/143904110.pdf

RICHARDSON, O. (2002): «Utilisation of the World Wide Web by wine producers», International Journal of Wine Marketing, vol. 14 (3), pp. 65-79.

SÁNCHEZ BARBERO, C. (2010): «Las páginas web de las bodegas. Una aproximación textual» en Vino, lengua y traducción. Valladolid, Universidad de Valladolid, Secretariado de Publicaciones e Intercambio Científico, pp. 335-352. 
